\title{
EFECTOS EXPRESIVOS DEL ENCABALGAMIENTO EN SONETOS ESPIRITUALES Y ESTÍO, DE JUAN RAMÓN JIMÉNEZ
}

\author{
José EnriQue Martínez FernándeZ
}

\begin{abstract}
Resumen: Primeramente se señala el lugar central que ocupan Sonetos espirituales y Estío en la trayectoria poética y la evolución métrica de Juan Ramón Jiménez, para detenerse después en los efectos expresivos atribuidos históricamente al encabalgamiento $\mathrm{y}$, más detalladamente, en los que emergen del uso de tal procedimiento en los sonetos del primer libro mencionado y en los versos de arte menor del segundo. La conclusión que se deriva del estudio es que el encabalgamiento enriquece extraordinariamente los finos matices expresivos de los versos del poeta.
\end{abstract}

Palabras clave: Encabalgamiento, efectos expresivos, sustantivo / adjetivo, encabalgamiento interno, Leyenda.

Abstract: This paper analyses the relevance of Sonetos espirituales and Estio in the poetic production and metrical evolution of Juan Ramón Jiménez. Moreover, it discusses the expressive effects historically attributed to enjambment, specifically, those that arise from the use of this technique in the sonnets of the first work mentioned above (Sonetos) and in the verse of the second. As a conclusion, we can affirm that the use of enjambment enriches the expressive nuances of the poems.

Key words: Enjambment, expresive effects, noun / adjective, internal enjambment, Leyenda. 



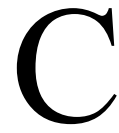

omo ha señalado Aurora de Albornoz ${ }^{1}$, Juan Ramón Jiménez reducía a tres las etapas de su poesía: una primera época "sensitiva" (hasta 1915 aproximadamente); una segunda época "intelectual" (se inicia con Diario de un poeta reciencasado, 1916, y se prolonga hasta que abandona España en 1936); y una tercera época "suficiente" o "verdadera" (desde 1936 hasta su muerte). En ese esquema, Sonetos espirituales (1913-1915) (1917) y Estío (escrito en 1915 y publicado en 1916) son libros que cerrarían una etapa, la segunda. La crítica suele indicar lo que el conocimiento y el amor por Zenobia supusieron creativamente para el poeta de Moguer a partir de 1913, concretamente en relación con Sonetos espirituales y Estío. Bástenos una cita larga, pero muy significativa, de Ricardo Senabre:

De 1913 a 1915 se produce un giro radical en la obra de Juan Ramón Jiménez, a raíz de su encuentro con Zenobia y el noviazgo subsiguiente. El poeta retira cautelosamente de la imprenta el volumen Libros de amor, constituido en gran parte por la reelaboración poética -muy explícita, sin embargo- de las actividades eróticas de Juan Ramón durante su estancia en el sanatorio del doctor Lalanne. Cambia de caligrafía - dato menos irrelevante de lo que podría parecer- y publica la versión primitiva de Platero y yo (1914), donde estampa por primera vez su nombre completo, abandonando la forma "Juan R. Jiménez" que había aparecido en todos los libros anteriores. Y existen otros indicios no menos significativos. A lo largo del noviazgo compone los poemas de Estío y el único libro de sonetos de factura clásica de toda su producción -los Sonetos espirituales-, no sólo porque las circunstancias favorecen la galvanización del

\footnotetext{
${ }^{1}$ Albornoz, Aurora de: "Juan Ramón Jiménez o la poesía en sucesión”, en Juan Ramón Jiménez. Nueva Antología. Barcelona: Península, 1973, p. 25.
} 
modelo petrarquista, sino porque la estrofa se convierte en señal de cierre -consciente, deliberado- de una trayectoria [...]. Nada tiene de particular, pues, que Estío marque nítidamente el nuevo derrotero. Si las sucesivas entregas poéticas juanramonianas habían sido hasta entonces, en apreciable proporción, libros "de amores", Estío es un libro "de amor", centrado en una amada única hacia la que converge todo (Senabre, 1998: 90)2.

Cronológicamente, a Sonetos espirituales y a Estio siguió Diario de un poeta recién casado, libro renovador, con cambio de tono, metro y estilo.

Desde el punto de vista métrico, en la poesía de Juan Ramón Jiménez señaló Navarro Tomás ${ }^{3}$ (1982: 262-263) tres modelos en sucesión cronológica:

1. Poemas en "diversos tipos de metros y estrofas", en sus primeros libros, Ninfeas, Almas de violeta (los dos de 1900) y Rimas (1902).

2. Empleo en cada libro de un solo tipo de verso, casi de manera exclusiva: el octosílabo en Arias tristes (1903), Jardines lejanos (1904) y Pastorales (escrito en 1905, publicado en 1911); el alejandrino en la mayor parte de $L a$ soledad sonora (su parte central en octosílabos), en los tres libros de Elegías (1908, 1909 y 1910) y en Melancolía (1912); el endecasílabo se inició en Poemas mágicos y dolientes (1911), se acentuó en Laberinto (1913) y se completó definitivamente en Sonetos espirituales.

3. Verso libre desde el Diario (1917) "anticipado en algunas composiciones de Estio" (1916) y que abarca Eternidades (1918), Piedra y cielo (1918), Poesía (1923), Belleza (1923), La estación total (1946) y Animal de fondo (1949).

Conviene precisar - lo hace Navarro Tomás- que no todos los libros de J.R.J. están comprendidos en ese proceso y esquema. De igual modo, indica que el cambio que supuso el Diario

\footnotetext{
${ }^{2}$ Senabre, Ricardo: "Juan Ramón Jiménez o la sublimación del erotismo", en Claves de la poesía contemporánea (de Bécquer a Brines). Salamanca: Almar, 1998, p. 90 .

${ }^{3}$ Navarro Tomás, Tomás: “Juan Ramón Jiménez y la lírica tradicional”, en Los poetas en sus versos. Desde Jorge Manrique a García Lorca. Barcelona: Ariel, 1982, pp. 262-263.
} 
métricamente no fue radical, pues "en ningún momento, ni aún en el período en que hizo mayor uso del verso libre, dejó de utilizar en un amplio género de composiciones la rima asonante o consonante y los metros regulares de once, nueve y ocho sílabas o de medidas menores" 4 .

De modo sintético, aquel esquema viene a reducirse a dos maneras básicas de versificar: por un lado, las composiciones van sometidas a sobria disciplina métrica (es el caso de Sonetos espirituales); por el otro, "la lírica de canción": composiciones en las que "aplicó diversos modelos y combinó variedad de recursos dando amplio margen a su propio sentido musical" y dando también "preferencia entre los moldes antiguos a los de arraigo más hondo y popular", como zéjel, villancico, romance y copla ${ }^{5}$ (al modelo de la "canción" adscribimos Estío). A estos dos tipos básicos, habría que añadir el verso libre a partir de Diario de un poeta recién casado.

\section{EFECTOS EXPRESIVOS DEL ENCABALGAMIENTO}

Al perturbar el ritmo fluyente de los versos, el encabalgamiento origina determinados efectos estilísticos o expresivos. Domínguez Caparrós ${ }^{6}$ hace ver que el encabalgamiento es, más que un fenómeno métrico, un fenómeno estilístico, algo, indica, que ya puso de manifiesto Navarro Tomás al incluirlo en su Métrica española entre los "complementos rítmicos": antítesis, paralelismos, repeticiones, armonía vocálica, etc. Así lo define Navarro Tomás: "Recurso expresivo que según los casos, sirve para la ligadura blanda y suave, para el contraste brusco y hasta para el efecto cómico, es el encabalgamiento, fundado en el desequilibrio entre verso y sintaxis"7. Para Balbín Lucas el encabalgamiento produce una "relevación intensiva" del primer elemento del sirrema y una "relevación tonal" del segundo

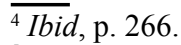

${ }^{5}$ Ibid, p. 266.

${ }^{6}$ Domínguez Caparrós, José: Métrica española. Madrid: Síntesis, 1993, p. 105.

${ }^{7}$ Navarro Tomás, Tomás: Métrica española. Reseña histórica y descriptiva. Madrid: Guadarrama, 1974 (4 ${ }^{\mathrm{a}}$ ed.), p. 42, nota al pie.
} 
elemento del sirrema encabalgado ${ }^{8}$. Si espigamos en los trabajos de Quilis y de Domínguez Caparrós sobre preceptivas y teorías métricas de siglos anteriores, los efectos del encabalgamiento podríamos reducirlos a tres básicamente: a) variedad de estilo, movimiento y viveza, frente a la monotonía de la esticomitia, aunque desde el mismo Herrera los tratadistas se oponen al uso continuado del encabalgamiento; b) el acompasamiento de los versos con el correr de la pasión o del sentimiento, como decía Munárriz, traductor de Hugo Blair; c) acercamiento del lenguaje poético a la lengua familiar, coloquial o dialogada.

En cuanto a los encabalgamientos abrupto y suave, ya Dámaso Alonso se encargó de señalar que aquél destaca, violenta o recorta la parte encabalgada, frente al endecasílabo suave, que prolonga "dulcemente un movimiento, una fluencia, ya material, ya espiritual" . Algunos poetas han aludido también al valor estilístico del encabalgamiento. Para Hierro, por ejemplo, el encabalgamiento "opone a un ritmo mental, conceptual, un ritmo sentimental" "10; por su parte, Luis Cernuda, en el conflicto entre lo que llama "ritmo del verso" y "ritmo de la frase", se decide por éste, lográndolo a través del encabalgamiento; la minoración del ritmo del verso en favor del ritmo de la frase se une en él a toda otra serie de fenómenos, como su "escasa simpatía por la rima" y por el "lenguaje suculento e inusitado", todo lo cual concuerda con su tendencia al "lenguaje hablado y el tono coloquial"

Frente a los posibles efectos generales, Senabre indica que "la función y el valor de los encabalgamientos son siempre contextuales, y sólo una peligrosa simplificación podría atribuirles un significado único y permanente"12; de ahí que el valor expresivo del encabalgamiento se haya visto en composiciones y autores concretos.

\footnotetext{
${ }^{8}$ Balbín, Rafael de: Sistema de ritmica castellana. Madrid: Gredos, 1962 (3 $3^{\mathrm{a}}$ ed.), p. 207.

${ }^{9}$ Alonso, Dámaso: Poesía española. Madrid, Gredos, 1950, p. 72.

${ }^{10}$ Hierro, José: "Palabras ante un poema", en VV.AA. Elementos formales de la lírica actual. Santander: Universidad Menéndez Pelayo, 1967, p. 91.

${ }^{11}$ Cernuda, Luis: "Historial de un libro", en Poesía y Literatura I y II. Barcelona: Seix Barral, 1971, p. 205.

${ }^{12}$ Senabre, Ricardo: "El encabalgamiento en la poesía de Fray Luis de León”. Revista de Filología Española, 1982, LXII, p. 41.
} 
EFECTOS EXPRESIVOS DEL ENCABALGAMIENTO EN

SONETOS ESPIRITUALES Y EN ESTÍO ${ }^{13}$

\section{En Sonetos espirituales}

En los Sonetos espirituales los encabalgamientos de más atractivos valores estéticos son los que rompen los sirremas formados por sustantivo y adjetivo (un $46 \%$ de los casos), particularmente aquellos en que la pausa métrica divide el adjetivo calificativo del sustantivo, sin duda por el efecto relevante que cobra el adyacente del sustantivo en posición marcada de final de verso. El calificativo depende semántica y gramaticalmente del sustantivo. Los calificativos y los determinativos "delimitan la extensión con que se enfoca el contenido propio del sustantivo (esto es, la aplicabilidad de su referencia)"14. Los calificativos añaden matices semánticos a la noción que expresa el sustantivo, pero emplazados en posición métrica marcada cobran una relevancia semántica y tonal inusual, superior a la del sustantivo al que califican o delimitan. Es el elemento secundario o adyacente el que se transforma en elemento primario o nuclear en la percepción lectora. De esta forma originan un "extrañamiento" que, sumado a la detención por pausa versal entre adjetivo y sustantivo, hace que la percepción sea más prolongada y amplíe, por ello, el efecto estético, como en su día observó el formalismo ruso. A la percepción relevante del calificativo contribuye, además, la rima. Tratándose de sonetos, la posición final de verso implica que el calificativo se intensifica también fónicamente, por cuanto la rima supone reiteración y tiempo, es decir, memoria y, por lo tanto, la asociación fónica con otros términos afines o disidentes semánticamente.

Sin ti, ¿qué seré yo? Tapia sin rosa, ¿qué es la primavera? ¡Ardiente, duro amor; arraiga, firme, en este muro de mi carne comida y ruinosa!

("Muro con rosa", primer cuarteto)

\footnotetext{
${ }^{13}$ Los textos se citan por Jiménez, Juan Ramón: Obra poética (tomo 1). Edición de Javier Blasco y Teresa Gómez Trueba, Madrid: Espasa-Calpe, 2005.

${ }^{14}$ Alarcos Llorach, Emilio: Gramática de la lengua española. Madrid: Espasa-Calpe, 1994, p. 83.
} 
Casi lo tuvo mi ardoroso anhelo un día, ¡clara mariposa pura!

... Pero la mariposa era la dura

sombra de un delirar de mi desvelo.

(“Ojos celestes", segundo cuarteto)

"Muro con rosa" es un poema de contenido amoroso que alegoriza el tú y el yo en la rosa y el muro. El muro es la imagen del yo o sujeto que habla; el tú es la rosa, el destinatario interno del poema, al que se apela y conmina: "arraiga, firme, en este muro...”, “¡Sí, ven a mí, agarra y desordena...”. El soneto es, por lo tanto, una súplica de amor, el deseo de que el muro o "tapia sin rosa" del primer cuarteto acabe siendo un muro primaveral, "todo cubierto de tus frescas flores", que es el verso último, verdadero epifonema o exclamación final que cierra y concluye el contenido y el deseo expresados en el soneto.

Los encabalgamientos son duro / amor y muro / de mi carne. "Duro es el calificativo de "amor"; visual y métricamente queda realzado, marcado, intensificado, más aún si en la lectura se sigue un modelo de ejecución rítmica, realizando la pausa versal. Pero aunque califica a "amor", el parentesco semántico con "muro", reforzado fónicamente por la rima, es evidente: "duro-muro"; la dureza se expresa por medio de un encabalgamiento abrupto, con cesura fuerte tras "amor"; el encabalgamiento abrupto resalta el fragmento del verso encabalgado, es decir, "amor"; el "duro amor" de la "tapia sin rosa" intensifica así su valor estilístico, queda recortado, aislado, imponiendo fuertemente su presencia, su "dureza".

Aún hemos de fijarnos en el contraste entre los dos encabalgamientos del cuarteto: duro lo hemos emparentado fónica $\mathrm{y}$ semánticamente con muro; pero a la vez contrastan uno y otro debido al otro elemento del sirrema: el amor y la carne, respectivamente; en efecto, el amor, un sentimiento "tierno", aparece calificado como duro; en cambio, el muro, al que solemos atribuir la calidad de "dureza", aparece referido a algo "ruinoso" como es el cuerpo, mi carne. El contraste se refuerza con otro que afecta a los tipos de encabalgamiento, abrupto el primero y suave y fluido el segundo. 
El mismo calificativo, en femenino, dura, aparece en el segundo cuarteto de "Ojos celestes", soneto que es otra alegorización del amor; la oposición inicial entre cielo azul y tierra oscura se reproduce en el terceto final, nuevo epifonema, bajo las formas respectivas de ojos celestes (a los que se refiere el sintagma "nunca bajáis") y carne umbrosa. En suma, se trata otra vez de un yo (tierra oscura, carne umbrosa) que anhela a un tú casi inalcanzable (azul del cielo, ojos celestes) y cuya imposible consecución -la distancia entre el tú y el yo, el cielo y la tierraproduce el desconsuelo del sujeto, "mi desconsuelo". Asistimos, pues, a la idealización del objeto amoroso.

Me referí al anhelo por parte del sujeto que habla en el poema de un tú casi inalcanzable. Ese casi ("cerca de", pero sin llegar a alcanzarlo) es el que se expande léxicamente en el segundo cuarteto, que comienza, justamente, con tal adverbio cuantitativo, "Casi lo tuvo mi ardoroso anhelo".

Nos detenemos en el encabalgamiento dura / sombra; no hace falta insistir sobre el realce de vario tipo (semántico, métrico, posicional) del calificativo dura, intensificado por su proximidad fónica y su alejamiento semántico con pura, su pareja de rima (tal contraste puede extenderse a las rimas en -ura del primer cuarteto, oscura y dulzura; se forman dos parejas en contraste semántico: oscura y dura frente a dulzura y pura). El contraste entre pura y dura, dos calificativos, subraya el que también existe entre esticomitia y encabalgamiento, asimismo manifestado léxicamente por la conjunción adversativa pero, "con que a un concepto se contrapone otro diverso o ampliativo del anterior", como indica el diccionario académico. "Clara mariposa pura", frente a "la mariposa era la dura / sombra..." reproducen, pues, el doble plano, celeste (tú) y terrenal (yo) sobre el que se balancea la construcción del poema. Lo que parece evidente es que en los versos encabalgados interesaba subrayar el calificativo dura, que acentúa el desconsuelo de no alcanzar la "mariposa pura". No dejemos a un lado, de todas formas, que la presencia de dura viene exigida por la rima de tres versos anteriores en -ura.

La rima, cuando la hay, no es un elemento métrico baladí. En un soneto es un elemento rítmico de primer orden. Y, como hemos ido viendo, difícilmente podemos entender algunos 
efectos estéticos del encabalgamiento en el soneto sin el apoyo de la rima, dado que el elemento encabalgante coincide con la palabra rimada. Pausa y rima delimitan el verso tradicional, y en nuestro caso el del soneto; la continuidad sintáctica de la frase entre versos encabalgados tiende a desvanecer la pausa métrica, por lo que la rima, como indica Quilis ${ }^{15}$, releva en sus funciones a la pausa versal. Dado que en los cuartetos de un soneto hay sólo dos rimas distintas para ocho versos, se establece entre ellos una relación fónica muy estrecha. Veamos los cuartetos de "Vigilia":

Todas las noches vienes a mi sueño, para decirme, dulce y quedamente, que mi empeño en echarte de mi frente, como a una maldición, es vano empeño.

Las torres que conquisto en el risueño día para el olvido, en la doliente noche las voy perdiendo, nuevamente... ¡Despierto esclavo si me dormí dueño!

El soneto expresa la obsesión amorosa del sujeto. De nuevo hay un yo sujeto y un $t u ́$ destinatario desde el primer verso, "Todas las noches vienes a mi sueño". Pero es el estado obsesivo del yo, incapaz de desprender su pensamiento del tú, lo que el poema desarrolla a través de una serie de contrastes que se inician en el segundo cuarteto y se prolongan hasta el final del soneto: en una serie los términos que denotan "mi empeño en echarte de mi frente": risueño día, conquisto, dueño, velar, sol, amanecida, día, traer ("no te traiga"); en la opuesta: doliente noche, perder, esclavo, desvelado, luna, anochecer, noche, partir ("tu partida").

Los versos encabalgados pertenecen al segundo cuarteto: risueño / día, doliente / noche, donde se muestra posicionalmente el contraste-oposición indicada: risueño-doliente, adjetivos colocados en final de verso encabalgante, y dia-noche, formas encabalgadas de los versos segundo y tercero respectivamente. La trascendencia significativa de los calificativos es evidente: día y noche no connotan cualidades positivas ni negativas fuera de contexto; son los calificativos risueño y doliente los que hacen

${ }^{15}$ Quilis, Antonio: Métrica española. Barcelona: Ariel, 1993 (7 $7^{\mathrm{a}}$ ed.), p. 86. 
del día algo grato y de la noche un tiempo aflictivo. La situación final de verso es en sí misma una posición marcada por la pausa rítmica, en desajuste con el sentido, pero tal relevancia, que es visual, se incrementa notoriamente con la rima, con el hecho de ser palabras también marcadas por la rima, singularmente en los cuartetos, donde cada palabra, risueño y doliente, rima con otras tres. En el poema "Vigilia" nos interesa el caso de risueño, cuya resonancia se acrecienta por la "rima intensa" que Rudolf Baehr definió como aquella "en la que además de la coincidencia de los sonidos posteriores al acento, se exige también la igualdad en uno o más sonidos anteriores"16; obsérvese: mi sueño; risueño; dormi dueño.

Las rimas imperfectas (-uéño, -iénte) e intensas proporcionan a los cuartetos un juego fónico muy rico, en combinación, como hemos visto, con los realces expresivos originados por el "deslazamiento" de determinados sintagmas en el segundo cuarteto.

En otros casos el contraste-oposición es aún más significativo, pues se da entre calificativos que riman entre sí, como celeste y agreste en los tercetos del soneto "Al invierno":

Mi lira quede sin su voz celeste y nunca más florezca mi camino, para la primavera, de flor pura.

¡Brisa, luz, fuerza, paz, salud, agreste dulzor, primer contento matutino...!

¡Ya el más grave dolor será ventura!

El poeta apela al invierno, "desde el estío", para que llegue son sus armas destructivas (vientos, fuegos, terremotos, etc.) a enterrar "la carne de mis secas ilusiones"; en ese estado de ánimo absolutamente desolado, el poeta reniega de los claros dones de su lira celeste, que -si no entiendo mal- eran los nombrados en el terceto último, brisa, luz, fuerza, paz..., para terminar con el epifonema del verso último, “ ¡Ya el más grave dolor será ventura!”, en el que parece expresar la idea de que cualquier dolor, comparado con el que ahora siente, será liviano.

El único encabalgamiento presente en los tercetos es el

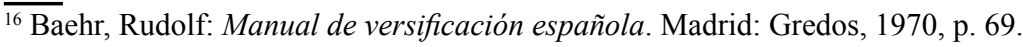


que parte y reparte en dos versos el sintagma agreste / dulzor. Aparentemente agreste contrasta por posición y sentido con celeste; pero mientras éste va precedido de voz y, por tanto, califica positivamente a un sustantivo que conocemos, que leemos previamente, agreste precede al sustantivo y establece el contraste inicial con celeste, hasta que el sustantivo dulzor reconduce la percepción inicial de algo áspero y terreno (frente a celeste) hacia un sentido positivo ("campestre" por ejemplo), en correspondencia con "brisa, luz, fuerza, paz...". La voz celeste era también agreste dulzor, y el sentido positivo de cada uno de los términos de la enumeración de los versos 12-13 se refuerza con el parentesco fónico no sólo entre agreste y celeste, sino también entre luz y salud, y con las aliteraciones por la repetición de la fricativa soda interdental /z/: luz, fuerza, paz, dulzor. La asonancia interna entre luz y salud, en la misma esfera semántica, se convierte en consonancia, interna también, pero entre dos términos opuestos semánticamente, dulzor y dolor.

En el sintagma sustantivo / adjetivo, el adjetivo adquiere relieve físico por otro procedimiento frecuente en los Sonetos espirituales: consiste en operar el "deslazamiento" en el orden adjetivo / sustantivo como en los casos anteriores, pero contrastando calificativo y sustantivo por su prolongada y su escasa materialidad fónica respectivamente; véanse estos casos de encabalgamiento: apetecida / paz ("Nostalgia"); polvorienta / rama ("Rama de oro"); resplandeciente / día ("A mi pena"); vehemencia / agria ("Mañanas"); soberana / noche ("Mañanas"); espantosa / soledad ("A un amigo"); bullanguero / volver ("Soledad"); amorosas / noches ("Esperanza"); violento / cartel ("Mayo espiritual"); pasajera / flor ("Mayo espiritual").

El calificativo suma su abultada fisicidad al privilegio del que ya goza por posición y rima. Observemos el cuarteto inicial de "Rama de oro":

Doliente rama de hojas otoñales que el sol divino enjoya y transparenta, cuando hurta el sol la nube, polvorienta rama es, de miserias materiales. 
Toda una sinfonía de sonidos nos espera: el acento dominante en sexta sílaba (dos primeros versos) y en cuarta (tercer verso) recae sobre la vocal grave /o/: hojas, enjoya, sol (también sol en el segundo verso, sílaba segunda). Es la vocal de mayor resonancia fónica en los tres versos primeros, resaltando las dos sílabas iniciales de otoñales y polvorienta, las dos en versos encabalgantes: hojas otoñales / que el sol... (oracional) y polvorienta / rama (sirremático). En los Sonetos espirituales el encabalgamiento oracional suele ser suave y fluido, prolongándose sosegadamente el sentido y el ritmo del verso encabalgante en el verso encabalgado o en los versos siguientes, como ocurre aquí en los dos primeros versos, en evidente contraste con el encabalgamiento abrupto polvorienta / rama es, de carácter además incidental o parentético, entendiendo que la frase es: "cuando hurta el sol la nube de miserias materiales"17. El verso final, en contraste fónico con los anteriores, orquesta una sucesión de vocales /a/, /e/ frente a la gravedad fónica de los versos anteriores. Pero quizá lo más llamativo sea el sentido parentético de polvorienta / rama es y, como tal, prescindible si sólo nos interesara el sentido, mera metáfora sugerida por doliente rama otoñal con que se inicia el soneto. Puede pensarse que fue la necesidad de la rima la que atrajo a polvorienta, pero nada impedía al poeta buscar otra forma; por otro lado, asuena con turbulencia (segundo cuarteto), palabra próxima semánticamente.

Otro caso interesante es el segundo cuarteto de "Luna de setiembre":

Pasaré entre las yedras del umbrío sendero, en que errará, perdidamente, el color y el olor de tanta ardiente

flor, muerta ya, de este marchito estío.

Los encabalgamientos son de tipo adjetivo / sustantivo, y el segundo con mayor cuerpo fónico del adjetivo en el verso encabalgante: umbrio / sendero, ardiente / flor. Su valor antepuesto

\footnotetext{
${ }^{17}$ Sin embargo, en Leyenda (Madrid: Visor, 2006: p. 525) la puntuación es distinta, con el consiguiente cambio sintáctico y de significado: "cuando hurta el sol la nube, polvorienta / rama es de miserias materiales"; también el verso 2 presenta una variante: "que el dios del sol enjoya y transparenta".
} 
es el típico del epíteto, que "revela una intención explicativa, descriptiva, de la realidad sugerida por el sustantivo", frente al pospuesto, que "señala una especificación que restituye la referencia propia del sustantivo" 18 . En cierto modo son calificativos tópicos y hasta esperables junto a los sustantivos correspondientes; si no lo son en este cuarteto es debido a la pausa rítmica y a ese "tiempo de espera" del que hablaron los formalistas rusos respecto al ritmo; aquí la espera temporal necesita resolverse, como en todo encabalgamiento, con la aparición del otro elemento del sintagma deslazado, en este caso los sustantivos sendero y flor. En los dos casos se trata de encabalgamientos abruptos, más perceptible tal carácter en el segundo debido al menor cuerpo fónico de flor, lo que aumenta también la violencia que implica tal encabalgamiento. La palabra flor queda resaltada no sólo por la posición inicial, sino por la cesura fuerte (también porque, resuelto el "tiempo de espera" del encabalgamiento, ardiente se percibe como epíteto tópico referido a la flor, sin que semánticamente especifique nada novedoso respecto al sustantivo). Pero a tal realce colaboran las rimas internas del cuarteto, muy próximas: color, olor, flor, palabras con una sola vocal grave, /ó/, y elementos sensitivos con que la flor manifiesta su colorido y su aroma.

En otros encabalgamientos del mismo tipo sirremático, el efecto estético procede de la falsa pista inicial que ofrece el verso encabalgante, reconducida en el verso encabalgado. Observemos dos ejemplos diferentes entre otros posibles:

¡Oh subir, oh caer de pena y gracia, correspondencia eterna de ideales cuidados, satisfechos vanamente!

Es el primer terceto de "Noches ideales", soneto en el que el desconsuelo actual sube a reflejarse en las mismas estrellas que bajaban como caricias, "hechas manos", en otras noches más dichosas. De ahí la oposición subir-caer en el terceto, en correlación con pena y gracia respectivamente.

${ }^{18}$ Alarcos Llorach, Emilio: Gramática de la lengua española, cit., p. 82. 
Leído el primer verso del terceto, el segundo nos hace percibir la palabra final, ideales, como sustantivo; pero al proseguir hacia el tercer verso, entendemos que nuestra percepción inicial es errónea y debemos reconstruir el sentido del verso anterior, puesto que ideales califica a cuidados; de este modo, la doble percepción de ideales como sustantivo y después como calificativo se suma, no desaparece (también en este aspecto -como en otros: rimas, ritmo- el verso es memoria).

El segundo cuarteto de "Voz de niño" dice así:
¿Del primer corazón que amó -¿lo vi?-
lucero matinal, digo, triunfal
grito que, trastornado, matinal
lucero creyó el sueño?... ¿Lo oí? ¡Sí!

La lectura del segundo verso nos lo hace ver, de inicio, con sentido pleno: "lucero matinal, digo, triunfal"; sólo al pasar al segundo verso nos apercibimos de lo erróneo de nuestra apreciación primera, pues triunfal no califica a lucero, sino a grito; una lectura consecuente reconstruirá el sentido del verso anterior, pero, como explicó Alarcos Llorach para un caso como éste, triunfal anticipa a grito del verso siguiente y lo reúne con lucero "como aspectos simultáneos del mismo contenido que quiere expresar el poeta" 19 . Las dudas y ambigüedades semánticas creadas por el encabalgamiento reproducen la corrección semántica que establece digo en el segundo verso o el término trastornado del verso siguiente, con su significado de "invertir el orden regular de una cosa" (DRAE), pues el triunfal grito lo creyó el sueño matinal lucero, nuevo encabalgamiento intensificador de tal trastorno, que se da también, como quiasmo, en la reiteración de lucero matinal, matinal lucero. La perplejidad, confusión o duda semántica expresada léxicamente se refuerza con la triple interrogación retórica del cuarteto, que en dos casos apela a los sentidos, ¿lo vi?, ¿Lo oí?, con resolución afirmativa sólo en la palabra final de la estrofa: ;Sí! Todos estos factores analizados crean un ritmo agitado, con numerosas cesuras en

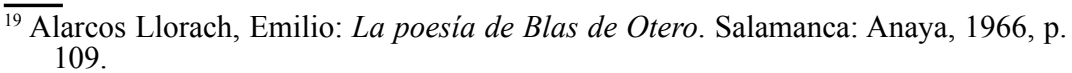


cada verso, ritmo que es una manifestación más del trastorno o confusión que el cuarteto expresa.

Cuando en el encabalgamiento "sustantivo / adjetivo", el adjetivo se ha resuelto en el verso encabalgado en una oración adjetiva especificativa, el encabalgamiento suele ser en la poesía juanramoniana suave, fluido, de prolongado desarrollo, como es lógico, pues la oración necesita mayor expansión léxica que un adjetivo. Un solo ejemplo, el terceto final de "Rosas devueltas", con dos encabalgamientos oracionales:

¡Todo se desentiende en la distancia

a que no ha de llegar esta tristeza

que nos ve sonreír, rosas, muriendo!

Nos detendremos, finalmente, en algunos encabalgamiento sirremáticos del tipo "sustantivo / complemento nominal"; este complemento equivale a un adjetivo o a una oración de relativo, por lo que el encabalgamiento presenta particularidades semejantes a las de "sustantivo / adjetivo" o "adjetivo / sustantivo". En los dos ejemplos siguientes ("adjetivo / sustantivo" y "sustantivo / complemento del nombre", respectivamente) los encabalgamientos parecen tener valores expresivos semejantes: extender imaginariamente la noción expresada por torre y alejamiento respectivamente:

A tu abandono opongo la elevada torre de mi pensamiento

¿Qué amena paz en este alejamiento de todo, ¡oh prado bello, que deshojas...

De mayor interés son los encabalgamientos de este tipo cuando van en serie:
¡Martirio del otoño! La dolencia del oro hace del jardín ardiente el verdadero ocaso, más vehemente y más sin fin que él. 


\section{Una inminencia}

de algo que no va a ser más, la frecuencia

del viento, el leve lamentar doliente

del gorrión, le dan a lo presente

anuncios vagos de mortal ausencia. ("Setiembre")

Aparte de otros valores, hay que contar inicialmente los que proporcionan los comienzos anafóricos de los versos, un procedimiento de insistencia, de repetición, como movidos los versos por un "impulso rítmico". Por otro lado, el encadenamiento de versos encabalgados, con inevitables cesuras interiores, parece borrar más efectivamente la pausa versal en la sucesión de los versos, si bien es algo que depende de la ejecución, lectura o recitación del receptor.

En "Setiembre" conviene destacar algunos otros factores estilísticos y de complementación rítmica: el encabalgamiento una inminencia / de algo deja a inminencia situada en posición marcada por pausa versal, rima y espacio en blanco; su aislamiento es una manera gráfica de indicar que algo apremiante va a suceder, de que algo queda en el aire, frente al espacio en blanco, como apremio o amenaza de lo que se presiente a punto de ocurrir; tal inminencia origina un verso encabalgado ("de algo que no va a ser más, la frecuencia") cuyo modelo rítmico yámbico (acentos en $4^{\mathrm{a}}$ sílaba y fijos en $6^{\mathrm{a}}$ y $10^{\mathrm{a}}$ ) se contraría con acentos en $1^{\mathrm{a}}, 5^{\mathrm{a}}$ y $7^{\mathrm{a}}$. Balbín llama antirrítmicos a estos acentos contiguos a uno rítmico $\left(6^{\mathrm{a}}\right)$; pero el poeta puede lograr diferentes efectos expresivos en el uso de estos mecanismos acentuales; así ocurre en este verso de Juan Ramón Jiménez, cuya cesura abrupta en $7^{\mathrm{a}}$ sílaba (más) parece subrayar con mayor violencia el riesgo de lo inminente; por otro lado, las posibles arritmias o faltas de ritmo regular de ese verso contrastan con la regularidad yámbica de los versos siguientes: acentos en $2^{\mathrm{a}}, 4^{\mathrm{a}}$, $8^{\mathrm{a}}$ y $10^{\mathrm{a}}$ sílabas (del gorrión no lleva acento en $2^{\mathrm{a}}$, pero sí en $4^{\mathrm{a}}$ por diéresis en go-rri-ón); tal regularidad rítmica es acorde con la "levedad" (leve) y "vaguedad" (vagos) semánticas que connotan, sin que falte una delicada alusión garcilasiana. 


\section{En Estío}

Estio es un poemario de ritmo vívido, movido por el uso variado de versos de arte menor. Muchos de los efectos estilísticos vistos en Sonetos espirituales se reiteran en Estío cuando se trata de encabalgamientos del mismo tipo: "La sombra parece / que te acerca más... / ¡Llega, por el túnel / de la oscuridad!”. Parece indudable que la relevancia de túnel en final de verso sugiere una más lenta y premiosa llegada de la oscuridad, efecto potenciado por la tardanza en llegar el apoyo tónico en el último verso, pues sólo porta acento en la sílaba penúltima: de la oscuridad.

En ocasiones el encabalgamiento subraya el contenido semántico del término encabalgante; así la lentitud en: "Aquella tortura, lento / sendero de la hermosura"; o la placidez, apoyado el efecto en el encabalgamiento suave, en: "iConfesión divina, plácida / correspondencia sin fin!"; o la infinitud en: "Está envuelta en ella misma, / de ella misma iluminada, / igual que en una infinita / atmósfera azul de gracia"; o el contraste entre triste y contento, hoy y mañana que expresa pero: "Estoy triste de hoy, pero / contento para mañana"; o la prolongación temporal sin fin en: “¡Cuándo ¡ay! Llegará, cuándo, / la luna de miel eterna / de los dos enamorados!".

No nos vamos a entretener en casos como estos ni en la fluidez rítmica de los encabalgamientos oracionales, ni en alguna "pista falsa" de interés relativo. Según mi apreciación, los efectos del encabalgamiento tienen menor vigor expresivo en los versos cortos, como los de Estío, debido a que el ojo lector capta casi simultáneamente el final del verso encabalgante y el principio del encabalgado, perdiendo así efectividad por la casi inexistencia de ese "tiempo de espera" que supone el paso de un verso a otro verso.

El efecto estético del encabalgamiento es mayor si contribuyen al mismo y a la vez otros factores, como el hipérbaton: "El oro nos engaña / de la estación..." ; o por la estructura del encabalgamiento en forma de quiasmo: "En la prisión enhiesta / de mi engreída mano"; o por determinados contrastes y afinidades semánticas: “...igual por el camino variable / de la eterna mudanza de tus días", donde la afinidad entre variable y mudanza contrastan por su sentido espacial (variable califica a camino) y temporal (mudanza de tus días) respectivamente, 
pero sólo en apariencia, pues camino es término metafórico de sentido temporal, como en el conocido verso de Dante: $\mathrm{Nel}$ mezzo del cammin di nostra vita...

Hay otros dos aspectos que diferencian Estío de Sonetos espirituales: el primero tiene que ver con las correcciones de Leyenda, que afectaron mínimamente a los Sonetos, pero considerablemente a determinados poemas de Estio; el segundo alude al interés de los encabalgamientos internos en el único poema en alejandrinos de Estio, "Amanecer de agosto".

En el paso de Estío a Verano verde y oro, en Leyenda, muchos encabalgamientos, con sus posibles valores expresivos de vario tipo desaparecieron.

¡Luz, sé sol; sé, olor, rosa;

melodía, sé lira;

lira, rosa, sol, cumbre

de mi vida! (Estio)

donde cumbre, en la "cima" del verso, aislada por el espacio en blanco y, significativamente, término novedoso en la reiteración que de la enumeración de los versos 1-2 se realiza de forma inversa en el verso 3, deja de ser término marcado en la disposición de los versos en Leyenda, que convierte los cuatro versos (cuatro heptasílabos y un tetrasílabos) en dos alejandrinos, para lo cual necesita introducir la palabra única en el segundo, manteniendo, eso sí, el encabalgamiento interno cumbre / única:

¡Luz, sé sol; sé, olor, rosa; melodía, sé lira;

lira, rosa, sol, cumbre única de mi vida!

El poema XLVII de Estío es una silva libre impar que combina versos endecasílabos (siete versos), eneasílabos (los dos primeros), heptasílabos (tres versos) y trisílabos (un solo verso). La crítica ha destacado la importancia histórica de Juan Ramón Jiménez en la adopción de esta variante de la silva libre por las generaciones futuras ${ }^{20}$. El sujeto del poema, tras un momento

${ }^{20}$ Paraíso, Isabel: La métrica española en su contexto románico. Madrid: Arco Libros, 2000, p. 200. 
de exaltación (¿amorosa?), de vuelta a los asuntos cotidianos, recuerda aquel momento cimero de "hace casi nada":

De un incoloro casi verde, vehemente e inmenso cual mi alma, me llevaba el ocaso

a todo.

...Nada hay que yo, esta tarde, conocido no haya.

...Ahora, de vuelta ya, como yo mismo,

en la playa diaria,

me pongo a recordar, entre la sombra

que avanza

-cantado de las olas de la sangre,

cristal de luz, que sube, puro, y baja-,

de tantas cosas y de tantos tiempos

vistas, pasados hace casi nada.

Aunque podríamos aludir a otros versos deslazados (entre la sombra / que avanza), nos detendremos en los dos últimos versos, en los que la correlación de dos sustantivos (cosas, tiempos) con los dos calificativos (vistas, pasados) aparece separada en dos versos, con lo que el paso del verso encabalgante, terminado en tantos tiempos, a otro verso que se inicia con vistas, es decir, de un masculino a un femenino, produce inevitable "extrañamiento" que el lector ha de reconducir al establecer la mencionada correlación gramatical y semántica.

La versión de Leyenda agrupa varios de los versos de Estío, dando lugar a un poema de seis versículos, en el sentido que lo entiende Márquez, "verso compuesto incluido en el verso libre de ritmo endecasilábico"21; de esta manera, los dos primeros versos de Estío forman el primer versículo de Leyenda; los tres siguientes, el segundo de la nueva versión; los dos siguientes, el tercero, etc., hasta llegar a los dos versos que nos interesan, los dos últimos de la versión de Estío, que en Leyenda forman el último versículo, en el que ha desaparecido el encabalgamiento con sus efectos (entre ellos también el de dilatación temporal que suponía tantos tiempos en final de verso y con el espacio

${ }^{21}$ Márquez, Miguel Ángel: "El versículo en el verso libre de ritmo endecasilábico", $B H S, 2000$, LXXVII, p. 218. 
en blanco que se creaba antes de abordar el verso encabalgado):

de tantas cosas y de tantos tiempos vistas, pasados hace casi nada

No parece que correcciones como las mencionadas, en Leyenda, sean especialmente felices.

"Amanecer de agosto" es el único poema en alejandrinos de Estío. De él nos interesan aquí los encabalgamientos interiores entre los hemistiquios heptasilábicos; la pausa en el interior de versos compuestos (cesura para otros ${ }^{22}$ ) impide la sinalefa y regulariza sobre terminación llana los finales de verso. La ausencia de sinalefa la observamos, por ejemplo, en este alejandrino: "el carmín del naciente, en cauces medio secos". Y la equivalencia de finales agudos, llanos y esdrújulos la vemos en alejandrinos con palabra esdrújula o aguda como fin del primer hemistiquio: "¡Estancias que una víspera dejó abiertas, ahogadas...”; "de ciudades que aún son y que ya no veremos".

El encabalgamiento medial o interior tiene, en principio, "valores estilísticos similares a los del encabalgamiento versal"23; pero, desde mi punto de vista, es menos perceptible, visualmente no existe y, por lo tanto, depende de la ejecución, es decir, de la recepción en gran parte.

"Amanecer de agosto" se compone de versos con gran riqueza de encabalgamientos internos, pues los hallamos de tipo sirremático y oracional. Los primeros deslazan sirremas como sustantivo / adjetivo (los vivos / amados; llanos / tristes), sustantivo / complemento nominal ( $\mathrm{fin} /$ del silencioso pueblo; amanecer / de frío; salida / de la cueva) y preposición / sustantivo (;Trenes que pasan por / el sol rojo ladrillo), con la conversión contextual en aguda de la partícula átona por; hay, además, dos encabalgamientos oracionales (la boca / que ayer besaba;

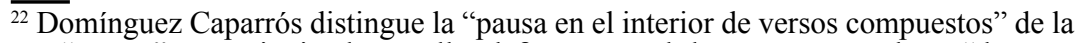
"cesura", que, siguiendo a Bello, define como el descanso que se hace "después de una palabra portadora de acento importante en algunas clases de versos largos" (Métrica española, cit., p. 102). Paraíso, siguiendo a Quilis, llama "cesura" al "tipo de pausa que se produce entre los hemistiquios de un verso compuesto" ( $\mathrm{La}$ métrica española en su contexto románico, cit., p. 97).

${ }^{23}$ Domínguez Caparrós, José: Diccionario de métrica española. Madrid: Alianza Editorial, 1999, p. 132.
} 
¡besos apasionados / que al alba...!). Algunos de estos encabalgamientos merecen ser destacados:

-Se sabe que los vivos amados que están lejos, están lejos, que están muertos los que están muertos

La pausa entre vios y amados crea una cierta ambigüedad: amados es calificativo de vivos, pero la pausa sugiere una forma sustantiva y una frase incidental, "amados que están lejos".

Sobre el despierto fin del silencioso pueblo

La pausa acentúa la terminación que significa fin y adelanta o realiza previamente el sentido de silencioso que sigue.

¡Campos en que una, antes, amó a otro, pinos tristes tristes veredas, llanos tristes, tristes cabezas!

En esa enumeración, el calificativo tristes va alternando su posición; dentro del verso segundo, llanos tristes parece reforzarse por su posición central, en quiasmo tanto con el sintagma precedente, tristes veredas, como con el siguiente, tristes cabezas; el deslazamiento llanos / tristes introduce un factor nuevo (el encabalgamiento interno) en la serie de cuatro términos con el mismo calificativo, como si la pausa dilatara imaginariamente la extensión de la llanura; pero, una vez más, sus efectos expresivos dependen de la percepción de la pausa en la lectura silenciosa o de la ejecución de la misma en la recitación.

Los 24 alejandrinos se reproducen en Leyenda como 12 versículos que habría que analizar como una suma de segmentos heptasilábicos (analizados así, cada versículo es la suma de cuatro heptasílabos); la nueva disposición diluye la posible percepción de los encabalgamientos internos; de hecho no creo que pueda hablarse de encabalgamientos entre los segmentos heptasilábicos, como en el caso siguiente, en el que dos alejandrinos de la versión de Estío aparecen dispuestos como un solo versículo en Leyenda:

¡Estancias que una víspera dejó abiertas, ahogadas de rosa, ardientemente, por el oro primero! 
Por otro lado, la nueva forma tipográfica afecta a la disposición de las rimas, que, en determinados versos han pasado a ser rimas internas ${ }^{24}$.

Como conclusión derivada de este estudio, puede decirse que con el uso del encabalgamiento, Juan Ramón Jiménez enriqueció extraordinariamente y con gran finura los matices expresivos de sus versos.

$\overline{{ }^{24} \mathrm{En}}$ Estio hay tres pareados alejandrinos con asonancia en é-o (rima común a los versos pares del resto del poema) marcados con letra cursiva (algo que se omite en Leyenda); al disponer cada pareado como un solo versículo, la rima del primer alejandrino se convierte en rima interior; en Leyenda, "Amanecer de agosto" es una serie de versículos asonantados con numerosas rimas interiores. 